\title{
Comparing the Effects of Ultrasound and Microwave Physiotherapy Treatments on Knee Osteoarthritis by Measuring Osteocalcin Level and Erythrocyte Sedimentation Rate in Blood
}

\author{
Shna Wrya Hawez ${ }^{1 \star}$, Shereen I. Hajee ${ }^{1}$
}

${ }^{1}$ Biophysics Unit, Department of Basic Science, College of Medicine, Hawler Medical University (HMU), Erbil, Kurdistan Region, IRAQ *Corresponding Author: shna.werya@hmu.edu.krd

Citation: Hawez SW, Hajee SI. Comparing the Effects of Ultrasound and Microwave Physiotherapy Treatments on Knee Osteoarthritis by Measuring Osteocalcin Level and Erythrocyte Sedimentation Rate in Blood. Electron J Gen Med. 2020;17(3):em193. https://doi.org/10.29333/ejgm/7810

ARTICLE INFO

Received: 18 Oct. 2019

Accepted: 27 Jan. 2020

\section{ABSTRACT}

Background and Objectives: Osteoarthritis is an inflammatory and degenerative joint disease, causing pain, musculoskeletal disorders and would affect functionality, daily life activities and quality of life. Comparing the effects of ultrasound and microwave physiotherapy treatments on knee osteoarthritis by measuring osteocalcin level and erythrocyte sedimentation rate in blood.

Methods: In a cross-sectional study conducted in in Hawler teaching hospital and Rzgari teaching hospital over the period December 2018 to May 2019, 30 patients with knee joint osteoarthritis were recruited. Half of them were provided with ultrasound physiotherapy treatment, and half with microwave physiotherapy treatment. The level of serum osteocalcin and erythrocyte sedimentation rate in blood were measured in both groups before and after the treatment with lasted for one month. The collected data were analyzed through paired and independent samples t-test using Statistical Package for the Social Sciences (version 18).

Results: Most of the patients (73.3\%) were females. Right knee osteoarthritis was the most prevalent with 13 patients, followed by bilateral knee osteoarthritis with 10 cases, and left knee osteoarthritis with 7 patients. The results indicated that ultrasound physiotherapy treatment had a significant effect on the level of serum osteocalcin $(p=0.01)$ and erythrocyte sedimentation rate in blood $(p=0.000)$. It was also seen that microwave physiotherapy treatment had a significant effect on erythrocyte sedimentation rate in blood $(p=0.000)$, while its effect on the level of serum osteocalcin was not significant $(p=0.53)$.

Conclusion: Based on the data collected from the present study, there is sufficient evidence to indicate that ultrasound and microwave physiotherapy interventions can reduce pain and improve function in those with knee OA.

Keywords: knee joint osteoarthritis, ultrasound physiotherapy, microwave physiotherapy, osteocalcin level, erythrocyte sedimentation rate

\section{INTRODUCTION}

As the most common type of arthritis, osteoarthritis (OA) has been regarded as one of the leading causes of decline in the functions of the body and decreased quality of life (1). Clinical observations have revealed that patients suffering from osteoarthritis undergo other complications, including occasional effusion in the joints, tenderness and ache with local inflammation, crepitus, stiffness, and movement limitation (2). Development of osteoarthritis is associated with a number of mechanical and biological factors including loss of articular cartilage and subchondral bone sclerosis $(3,4)$. Osteoarthritis can afflict both young and old individuals; however, it has been reported to be more common among adults who are between 55 and 64 years old (5).
Very recent epidemiological surveys have shown that symptomatic knee osteoarthritis has a prevalence rate of $8.1 \%$, with women having higher prevalence rates compared to men. It has also been indicated that osteoarthritis is also the $12^{\text {th }}$ leading cause of disability (6). Knee osteoarthritis is a musculoskeletal condition which is prevalent among older people, leading to disability and a remarkable decrease in the quality of their lives. It is also associated with physical pain and imposes remarkable economic burden on health care systems all over the world. It is quite predictable that the prevalence rate of the disease is rising because the global population is getting older and older every year. Due to the fact that the world population is getting older, such that $25 \%$ of the people in the US will be over 65 years old by 2040 , it has been predicted that knee osteoarthritis will become a serious challenge in the public health (7). 
The pathogenesis of knee osteoarthritis is not completely known yet; however, the key feature in OA has been referred to as the unbalanced differentiation and proliferation of chondrocytes. In addition to this, there are some other factors that play a role in development of $O A$, including cross-linked hyaluronates, GDF-5, C-reactive proteins (CRP), Gel-200, and erythrocyte sedimentation rate (ESR) (8).

Treatment of osteoarthritis is mainly aimed at raising knowledge about the disease and controlling ache and stiffness of the joint in order to improve their function. Surgery and pharmacological and non-pharmacological treatments have been introduced as common osteoarthritis treatments (9). Over recent years, there has been increasing tendency toward non-pharmacological therapies such as electroanalgesia, laser therapy, and ultrasound for the management of pain caused by osteoarthritis. In 1994, the Food and Drug Administration (FDA) approved ultrasound as a safe and non-invasive physiotherapy for musculoskeletal conditions, and it has been used for this purpose since then $(10,11)$. It has been reported that ultrasound physiotherapy results in the relief of osteoarthritis symptoms and has high potential cartilage healing effects. Moreover, it has been indicated that ultrasound physiotherapy regulates inflammatory responses, helps with cartilage repair, and enhances the formation of collagen (12). Phonophoresis can also be achieved with the help of ultrasound; therefore, it is a non-invasive method of medications to tissues under the skin. It has also been demonstrated by clinical trials that phonophoresis can be used as a more effective strategy for relief of pain associated with symptomatic knee osteoarthritis than conventional non-drug ultrasound treatments. However, using of phonophoresis in physical therapy is not wellsupported by clinical evidence $(13,14)$.

According to the results of a recent review that included 10 randomized controlled trials conducted over the period of 1991-2014, ultrasound was introduced as a safe and noninvasive physiotherapy to relieve pain caused by osteoarthritis and improve physical functions (15). Another nonpharmacological treatment to manage osteoarthritis is microwave physiotherapy treatment which is a physical deep heating physical agent and has been referred to as a beneficial method along with ultrasound and short-waves diathermy to manage and control pain associated with osteoarthritis of different levels of severity (16).

Non-pharmacological treatments aimed at improving OA symptoms are highly recommended, and it has long been recognized that physiotherapy treatments have a significant role in managing patients with knee joint osteoarthritis. Physiotherapy treatments consists of some common techniques, such as manual therapy, insoles and shoes, taping, and exercise which are effective in decreasing the pain and other symptoms associated with knee joint osteoarthritis (17). Knee joint osteoarthritis is typically treated and managed through physiotherapy which is a non-pharmacological intervention that is recommended by the European League Against Rheumatism and the American College of Rheumatology (18). It includes some treatment techniques like exercising, manual therapy, taping the knee, and training the patients to learn how to manage their OA themselves. In most studies of physiotherapy for knee joint osteoarthritis, individual components have been assessed, which has failed to indicate typical clinical practice. Several studies have focused on the effect of physiotherapy on OA management. Some studies employed a placebo comparison group $(19,20)$. It has been reported that physiotherapy is beneficial for $\mathrm{OA}$ management (21). It has also been reported thatodgdf has a strong effect on pain outcomes (22).

According to what was mentioned above, the present study was carried out in order to determine and compare the effects of ultrasound and microwave physiotherapy treatments on knee joint osteoarthritis by measuring the level of serum osteocalcin and erythrocyte sedimentation rate in blood.

\section{PATIENTS AND METHODS}

The present cross-sectional study was carried out in Hawler teaching hospital and Rzgari teaching hospital over the period December 2018 to May 2019. The study sample consisted of 30 men and women who were diagnosed with knee joint osteoarthritis (OA) based on the clinical and radiographic x-ray in the two mentioned hospitals. They aged 40 or older with moderate (Kellgren-Lawrence grade II or III), mono or bilateral knee OA, and pain lasting for at least three weeks. While sampling, patients who were receiving physiotherapy treatment by ultrasound and microwave instruments were excluded from the study.

The recruited patients were divided into two groups. One of the groups was exposed to microwave for 15 mints per day, while the other group was exposed to ultrasound for 5 minutes per day. Each case received the treatment 4 times a week. The treatment lasted for one month. Osteocalcin test and erythrocyte sedimentation rate (ESR) test were carried out for all of the patients before and one month after the physiotherapy treatments.

The collected data were analyzed using SPSS (version 18.0). In so doing, multiple pairwise within two groups was performed by means of paired t-tests where statistical significance for osteocalcin of ultrasound was set at $\mathrm{P}<0.05$ and it was highly significant for ESR test for both ultrasound and microwave treatments. Normal analysis of the two groups, and completely independent samples t-test and rank sum test were used to compare and analyze any differences between the groups before and after the treatment.

In order to take the ethical considerations into account, informed consent was obtained from all of the patients for participating in the study and attending regular follow-ups. Moreover, the research was approved by the Ethics Committee of College of Medicine.

\section{RESULTS}

The results revealed that out of the 30 patients, 22 were females and 8 were males. Regarding their knee OA side, it was observed that 7 females and 3 males had knee OA in both knees (bilateral), 10 females and 3 males had right knee OA, and 5 females and 2 males had left knee OA (See Table 1).

Of the 30 patients with knee joint OA, 15 were treated with ultrasound and 15 with microwave. Out of the 10 patients with bilateral knee OA, 5 were treated with ultrasound and 5 with microwave. Of the 13 patients with right knee OA, 7 were treated with ultrasound and 6 with microwave. Out of the 7 patients with left knee OA, 3 were treated with ultrasound and 4 with microwave (See Table 2). 
Table 1. Distribution of knee joint OA across genders and knee OA side

\begin{tabular}{|c|c|c|c|c|c|}
\hline & & & \multicolumn{2}{|c|}{ Gender } & \multirow{2}{*}{ Total } \\
\hline & & & Male & Female & \\
\hline \multirow{6}{*}{ Knee joint OA } & \multirow{2}{*}{ Bilateral knee OA } & Count & 3 & 7 & 10 \\
\hline & & $\%$ within knee joint OA & $30.0 \%$ & $70.0 \%$ & $100.0 \%$ \\
\hline & \multirow{2}{*}{ Right knee OA } & Count & 3 & 10 & 13 \\
\hline & & $\%$ within knee joint OA & $23.1 \%$ & $76.9 \%$ & $100.0 \%$ \\
\hline & \multirow{2}{*}{ Left knee OA } & Count & 2 & 5 & 7 \\
\hline & & $\%$ within knee joint OA & $28.6 \%$ & $71.4 \%$ & $100.0 \%$ \\
\hline \multirow{2}{*}{\multicolumn{2}{|c|}{ Total }} & Count & 8 & 22 & 30 \\
\hline & & $\%$ within knee joint OA & $26.7 \%$ & $73.3 \%$ & $100.0 \%$ \\
\hline
\end{tabular}

Table 2. Distribution of knee joint OA across physiotherapy instruments

\begin{tabular}{|c|c|c|c|c|c|}
\hline & & & \multicolumn{2}{|c|}{ Physiotherapy instruments } & \multirow{2}{*}{ Total } \\
\hline & & & Ultrasound & Microwave & \\
\hline \multirow{6}{*}{ Knee joint OA } & \multirow{2}{*}{ Bilateral knee OA } & Count & 5 & 5 & 10 \\
\hline & & $\%$ within knee joint OA & $50.0 \%$ & $50.0 \%$ & $100.0 \%$ \\
\hline & \multirow{2}{*}{ Right knee OA } & Count & 7 & 6 & 13 \\
\hline & & $\%$ within knee joint OA & $53.8 \%$ & $46.2 \%$ & $100.0 \%$ \\
\hline & \multirow{2}{*}{ Left knee OA } & Count & 3 & 4 & 7 \\
\hline & & $\%$ within knee joint OA & $42.9 \%$ & $57.1 \%$ & $100.0 \%$ \\
\hline \multirow{2}{*}{\multicolumn{2}{|c|}{ Total }} & Count & 15 & 15 & 30 \\
\hline & & $\%$ within knee joint OA & $50.0 \%$ & $50.0 \%$ & $100.0 \%$ \\
\hline
\end{tabular}

Table 3. Comparing physiotherapy instruments before and after treatment based on osteocalcin and ESR tests

\begin{tabular}{|c|c|c|c|c|c|c|c|c|c|c|}
\hline \multirow{3}{*}{\multicolumn{3}{|c|}{ Physiotherapy instruments }} & \multicolumn{5}{|c|}{ Paired Differences } & \multirow{3}{*}{$\mathbf{t}$} & \multirow{3}{*}{ df } & \multirow{3}{*}{$\begin{array}{l}\text { Sig. (2- } \\
\text { tailed) }\end{array}$} \\
\hline & & & \multirow[t]{2}{*}{ Mean } & \multirow{2}{*}{$\begin{array}{c}\text { Std. } \\
\text { Deviation }\end{array}$} & \multirow{2}{*}{$\begin{array}{l}\text { Std. Error } \\
\text { Mean }\end{array}$} & \multicolumn{2}{|c|}{$\begin{array}{c}95 \% \text { Confidence Interval } \\
\text { of the Difference }\end{array}$} & & & \\
\hline & & & & & & Lower & Upper & & & \\
\hline \multirow{2}{*}{ Ultrasound } & $\begin{array}{c}\text { Pair } \\
1 \\
\end{array}$ & $\begin{array}{c}\text { Osteocalcin test before } \\
\text { and after treatment }\end{array}$ & -.66933 & .88042 & .22732 & -1.15689 & -.18177 & -2.944 & 14 & .011 \\
\hline & $\begin{array}{c}\text { Pair } \\
2 \\
\end{array}$ & $\begin{array}{c}\text { ESR test before and } \\
\text { after treatment }\end{array}$ & 9.26667 & 4.30061 & 1.11041 & 6.88507 & 11.64826 & 8.345 & 14 & .000 \\
\hline \multirow{2}{*}{ Microwave } & $\begin{array}{c}\text { Pair } \\
1\end{array}$ & $\begin{array}{l}\text { Osteocalcin test before } \\
\text { and after treatment }\end{array}$ & .05133 & .30997 & .08003 & -.12032 & .22299 & .641 & 14 & .532 \\
\hline & $\begin{array}{c}\text { Pair } \\
2\end{array}$ & $\begin{array}{l}\text { ESR test before and } \\
\text { after treatment }\end{array}$ & 4.53333 & 3.27036 & .84440 & 2.72227 & 6.34440 & 5.369 & 14 & .000 \\
\hline
\end{tabular}

The results of treating the patients with ultrasound and microwave were compared through osteocalcin test and erythrocyte sedimentation rate (ESR) test. The results obtained from osteocalcin revealed that treatment with ultrasound led to a significant difference in knee joint $O A(p=0.01)$, while treatment with microwave did not bring about a significant difference $(p=0.53)$. Comparing the effects of treatment with ultrasound and microwave through ESR test indicated that both treatment methods led to significant differences $(p=0.000)$ (See Table 3).

\section{DISCUSSION}

Osteoarthritis $(O A)$ is a prevalent disease which can lead to significant morbidity. Research has revealed that $O A$ is more prevalent among women than men, with about half of them suffering from OA in their right knees (23). Similarly, the results of the present study showed that $73.3 \%$ of the patients were females. This finding is also in agreement with those of the study carried out by Yasemin et al who referred to knee joint $O A$ as an age-related condition that occurs more frequently in females than in males (24). Pain while movement is the most common symptom of $\mathrm{OA}$ which restricts individuals' daily activities which in turn has a negative effect on the quality of their lives. Conflicting results have been reported for the effectiveness of treatment in knee OA (25). According to the 2010 Osteoarthritis Research Society International recommendations for the management of hip and knee $O A$, the optimal osteoarthritis management should include a combination of pharmacological and non-pharmacological modalities such as physical therapy; however, ultrasound has not been referred to as a treatment method (26).

The effectiveness of therapeutic ultrasound has been investigated in some studies which have reported controversial results in terms of the clinical effectiveness of ultrasound $(27,28)$. Therefore, the effectiveness of ultrasound on knee joint osteoarthritis is not conclusive yet. In their review, Cook et al reported that ultrasound treatment has no significant advantage over placebo or short-wave diathermy for knee joint osteoarthritis (29). Other studies including the one carried out by Rutjes et al revealed that ultrasound physiotherapy might be beneficial for patients with knee joint osteoarthritis. They also pointed out that the conclusions regarding the effectiveness of therapeutic application of the ultrasound are limited due to the poor reporting of the stage of $\mathrm{OA}$, the population, and the features of the device (30). 
In their trial, Jan et al tried to determine the efficacy of ultrasound in relieving pain and stiffness in patients with knee joint osteoarthritis and chronic knee contracture. According to the results of their study, ultrasound was not found to have a significant role in the management of patients with chronic knee stiffness and osteoarthritis (31). On the contrary, the results of the present study indicated that ultrasound is effective in managing $O A$. The difference between the study conducted by Jan et al. (31) and the present one might be related to the fact that they applied ultrasound 3 minutes and its intensity was not constant, while in the present study ultrasound frequency and intensity were constant, and the duration was $5 \mathrm{~min}$. The present study proved the effectiveness of ultrasound in managing knee $\mathrm{OA}$. In line with this finding, Ozgonenel et al who studied the effect of ultrasound and sham ultrasound as placebo on management of pain and other symptoms of knee OA reported that ultrasound led to better results in terms of treatment of knee joint osteoarthritis compared to the placebo (32).

Pain is a highly significant and remarkable symptom in knee osteoarthritis. It has been reported to be the result of some conditions that lead to changes in peri- and intraarticular and connective tissues. It has been indicated that pain associated with knee OA can be relieved and knee function can be improved by applying ultrasound physiotherapy $(28,32)$. Similarly, the results of the present study indicated that ultrasound physiotherapy is significantly effective in managing knee joint osteoarthritis.

In the present study, half of the patients with $O A$ received microwave physiotherapy as a treatment for their osteoarthritis. In this regard, it was seen that microwave physiotherapy, similar to ultrasound physiotherapy, had a significant effect on erythrocyte sedimentation rate in the blood, indicating the efficacy of this therapy on management of knee OA. This finding is in good agreement with those of the study carried out by Jorge et al who reported that physical deep heating physical agents like microwave, ultrasound, and short-waves diathermy are beneficial in managing and controlling pain associated with knee joint OA of different severity levels (16). Microwave physiotherapy along with intraarticular injection of hyaluronic acid has been reported to be effective in relieving symptoms of knee OA; however, the efficacy of this method was reported to be lower than that of radiofrequency diathermy due to the fact that the two methods have different heating features (33).

As indicated in the present study, ultrasound and microwave physiotherapies led to improvement in the level of serum osteocalcin and erythrocyte sedimentation rate in blood, indicating the effectiveness of these two techniques in controlling and managing knee $\mathrm{OA}$ and its symptoms. This finding can be justified by referring to the fact that nerve function and blood circulation improve as a result of regular exercise and monitoring, which in turn leads to reduced disability and mobility, enhanced stability, increased muscle strength, and improved muscle flexibility in patients with knee joint osteoarthritis (34). Similarly, Shakoor et al concluded that isometric quadriceps muscle exercise in patients with chronic knee OA can lead to improved functional ability, increased range of motion, and decreased pain associated with knee OA (35).

\section{CONCLUSION}

Physiotherapy interventions can lead to a decrease in knee pain and improvement in knee function in patients with knee osteoarthritis. Ultrasound and microwave physiotherapy treatments were found to be effective in controlling the level of serum osteocalcin and erythrocyte sedimentation rate in blood, revealing their effectiveness in managing knee joint osteoarthritis.

\section{REFERENCES}

1. Sharma L, Kapoor D, Issa S. Epidemiology of osteoarthritis: an update. Curr Opin Rheumatol. 2006;18(2):147-56. https://doi.org/10.1097/01.bor.0000209426.84775.f8 PMid: 16462520

2. Woolf AD. Driving musculoskeletal health for Europe: EUMUSC.NET. Reumatismo. 2011;63(1):1-4. https://doi.org /10.4081/reumatismo.2011.1 PMid:21509343

3. Van der Kraan PM. Osteoarthritis year 2012 in review: biology. Osteoarthritis Cartilage. 2012;20(12):1447-50. https://doi.org/10.1016/j.joca.2012.07.010 PMid:22897882

4. Sherwood J. Osteoarthritis year in review 2018: biology. Osteoarthritis Cartilage. 2019;27(3):365-70. https://doi.org/10.1016/j.joca.2018.10.005 PMid:30808484

5. Bortoluzzi A, Furini F, Scire CA. Osteoarthritis and its management-epidemiology, nutritional aspects and environmental factors. Autoimmun Rev. 2018;17(11):1097104. https://doi.org/10.1016/j.autrev.2018.06.002 PMid:30213694

6. Tang X, Wang S, Zhan S, et al. The prevalence of symptomatic knee osteoarthritis in China: results from the China Health and Retirement Longitudinal Study. Arthritis Rheumatol. 2016;68(3):648-53. https://doi.org/10.1002/art.39465 PMid:26474054

7. Bennell KL, Hinman RS, Metcalf BR, et al. Efficacy of physiotherapy management of knee joint osteoarthritis: a randomised, double blind, placebo controlled trial. Ann Rheum Dis. 2005;64:906-12. https://doi.org/10.1136/ard. 2004.026526 PMid:15897310 PMCid:PMC1755542

8. Yoshioka K, Yasuda Y, Kisukeda T, et al. Pharmacological effects of novel cross-linked hyaluronate, Gel- 200, in experimental animal models of osteoarthritis and human cell lines. Osteoarthritis Cartilage, 2014;22:879-87. https://doi.org/10.1016/j.joca.2014.04.019 PMid:24792209

9. Nelson AE. Osteoarthritis year in review 2017: clinical. Osteoarthritis Cartilage. 2018;26(3):319-25. https://doi.org/10.1016/j.joca.2017.11.014 PMid:29229563 PMCid:PMC5835411

10. Devrimsel G, Metin Y, Serdaroglu BM. Shortterm effects of neuromuscular electrical stimulation and ultrasound therapies on muscle architecture and functional capacity in knee osteoarthritis: a randomized study. Clin Rehabil. 2019;33(3):418-27. https://doi.org/10.1177/0269215518817 807 PMid:30514113

11. Qi L, Tang Y, You Y, et al. Comparing the effectiveness of electroacupuncture with different grades of knee osteoarthritis: a prospective study. Cell Physiol Biochem. 2016;39(6):2331-40. https://doi.org/10.1159/000447925 PMid:27832623 
12. Rothenberg J. B, Jayaram P, Naqvi U, et al. The role of lowintensity pulsed ultrasound on cartilage healing in knee osteoarthritis: a review. PMR. 2017;9(12):1268-77. https://doi.org/10.1016/j.pmrj.2017.05.008 PMid:28606838

13. Beutler A. Musculoskeletal therapies: adjunctive physical therapy. FP Essent. 2018;470:16-20.

14. Luksurapan W, Boonhong J. Effects of phonophoresis of piroxicam and ultrasound on symptomatic knee osteoarthritis. Arch Phys Med Rehabil. 2013;94(2):250-5. https://doi.org/10.1016/j.apmr.2012.09.025 PMid:23063790

15. Zhang C, Xie Y, Luo X, et al. Effects of therapeutic ultrasound on pain, physical functions and safety outcomes in patients with knee osteoarthritis: a systematic review and metaanalysis. Clin Rehabil. 2016;30(10):960-71. https://doi.org/ 10.1177/0269215515609415 PMid:26451008

16. Jorge MSG, Zanin C, Knob B, Wibelinge LM. Effects of deep heating to treat osteoarthritis pain: systematic review. Rev Dor. São Paulo, 2017 Jan-Mar;18(1):79-84. https://doi.org/10.5935/1806-0013.20170016

17. Carolyn JP, Rana SH, Kim LB. Physiotherapy management of knee osteoarthritis. International Journal of Rheumatic Diseases. 2011;14:145-51. https://doi.org/10.1111/j.1756185X.2011.01612.x PMid:21518313

18. Jordan K, Arden N, Doherty $M$, et al. EULAR recommendations 2003: an evidence based approach to the management of knee osteoarthritis. Report of a task force of the Standing Committee for International Clinical Studies Including Therapeutic Trials (ESCISIT). Ann Rheum Dis. 2003;62:1145-55. https://doi.org/10.1136/ard.2003. 011742 PMid:14644851 PMCid:PMC1754382

19. Quilty B, Tucker M, Campbell R, et al. Physiotherapy, including quadriceps exercises and patellar taping, for knee osteoarthritis with predominant patello-femoral joint involvement: Randomized controlled trial. J Rheumatol. 2003;30:1311-17.

20. Zhang Y, Jordan JM. Epidemiology of osteoarthritis. Rheum Dis Clin North Am. 2008;34:515e29. https://doi.org/10.1016/j.rdc.2008.05.007 PMid:18687270 PMCid:PMC4384650

21. Zhang W, Moskowitz RW, Nuki G, et al. OARSI recommendations for the management of hip andknee osteoarthritis, part II: OARSI evidence-based, expert consensus guidelines. Osteoarthritis Cartilage. 2008;16:137e62. https://doi.org/10.1016/j.joca.2007.12.013 PMid:18279766

22. Binks DA, Gravallese EM, Bergin D, et al. Role of vascular channels as a novel mechanism for subchondral bone damage at cruciate ligament entheses in osteoarthritis and inflammatory arthritis. Ann Rheum Dis. 2015;74:196-203. https://doi.org/10.1136/annrheumdis-2013-203972 PMid:24095939 PMCid:PMC4283693

23. Rand SE, Goerlich C, Marchand K, et al. The physical therapy prescription. Am Fam Physician. 2007;76:1661-6.

24. Yasemin U, Berna T, Yesim A, et al. Therapeutic ultrasound versus sham ultrasound for the management of patients with knee osteoarthritis: a randomized double-blind controlled clinical study. International Journal of Rheumatic Diseases. 2012;15:197-206. https://doi.org/ 10.1111/j.1756-185X.2012.01709.x PMid:22462424
25. Akyol Y, Durmus D, Alayli G, et al. Does shortwave diathermy increase the effectiveness of isokinetic exercise on pain, function, knee muscle strength, quality of life, and depression in the patients with knee osteoarthritis? A randomized controlled clinical study. Eur J Phys Rehabil Med. 2010;46:325-36.

26. Zhang W, Nuki G, Moskowitz RW, et al. OARSI recommendations for the management of hip and knee osteoarthritis: part III: changes in evidence following systematic cumulative update of research published through January 2009. Osteoarthritis Cartilage 2010;18:476-99. https://doi.org/10.1016/j.joca.2010.01.013 PMid:20170770

27. Cetin N, Aytar A, Atalay A, et al. Comparing hot pack, shortwave diathermy, ultrasound, and TENS on isokinetic strength, pain, and functional status of women with osteoarthritic knees: a single-blind, randomized, controlled trial. Am J Phys Med Rehabil. 2008;87:443-51. https://doi.org/10.1097/PHM.0b013e318174e467 PMid: 18496246

28. Tascioglu F, Kuzgun S, Armagan O, et al. Short term effectiveness of ultrasound therapy in knee osteoarthritis. J Int Med Res. 2010;38:1233-42. https://doi.org/10.1177/ 147323001003800404 PMid:20925995

29. Cook SD, Salkeld SL, Patron LP, et al. The effect of lowintensity pulsed ultrasound on autologous osteochondral plugs in a canine model. Am J Sports Med. 2008;36:1733e41. 0363546508316766 PMid:18483198

30. Rutjes AW, Nuesch E, Sterchi R, et al. Therapeutic ultrasound for osteoarthritis of the knee or hip (Review). Cochrane Database Syst Rev. 2010;20:CD003132. https://doi.org/10.1002/14651858.CD003132.pub2

31. Jan $\mathrm{MH}$, Chai HM, Wang CL, et al. Effects of repetitive shortwave diathermy for reducing synovitis in patients with knee osteoarthritis: an ultrasonographic study. Phys Ther. 2006;86(2):236-44. https://doi.org/10.1093/ptj/86.2.236 PMid:16445337

32. Ozgonenel L, Aytekin E, Durmusoglu G. A doubleblind trial of clinical effects of therapeutic ultrasound in knee osteoarthritis. Ultrasound Med Biol. 2009;35:44-9. https://doi.org/10.1016/j.ultrasmedbio.2008.07.009 PMid:18829151

33. Takahashi K, Hashimoto S, Kurosaki H, et al. A pilot study comparing the efficacy of radiofrequency and microwave diathermy in combination with intra-articular injection of hyaluronic acid in knee osteoarthritis. J Phys Ther Sci. 2016;28(2):525-9. https://doi.org/10.1589/jpts.28.525 PMid:27065540 PMCid:PMC4793004

34. Made HSN, Ni Wayan T, Ari W, et al. The Combined Effect of Microwave Diathermy Treatment and Perturbation Training on Functional Ability in Individual with Knee Osteoarthritis. The 2nd International Nursing Conference. 2017.

35. Shakoor MA, Rahman MS, Azad AK, et al. Effects of Isometric Quadriceps Muscle Strengthening Exercise on Chronic Osteoarthritis of the Knee. Bangladesh Med Res Counc Bull. 2010;36:20-2. https://doi.org/10.3329/bmrcb.v36i1.5502 PMid:21280554 